\title{
Serum thyroglobulin before and after iodization of salt: an 11-year DanThyr follow-up study
}

\author{
Anne Krejbjerg ${ }^{1}$, Lena Bjergved ${ }^{2,3}$, Inge Bülow Pedersen ${ }^{1}$, Allan Carlée,4, \\ Nils Knudsen ${ }^{3}$, Hans Perrild ${ }^{3}$, Lars Ovesen ${ }^{5}$, Lone Banke Rasmussen ${ }^{6}$ and \\ Peter Laurberg ${ }^{1}$
}

'Departments of Clinical Medicine and Endocrinology, Aalborg University and Aalborg University Hospital, Sdr. Skovvej 15, DK-9000 Aalborg, Denmark, ${ }^{2}$ Research Centre for Prevention and Health, The Capital Region of Denmark, Glostrup, Denmark, ${ }^{3}$ Department of Endocrinology, Bispebjerg University Hospital, Copenhagen, Denmark, ${ }^{4}$ Diagnostic Centre, Region Hospital Silkeborg, Silkeborg, Denmark, ${ }^{5}$ Department of Gastroenterology, Slagelse Hospital, Slagelse, Denmark and ${ }^{6}$ Department of Nutrition, National Food Institute, Technical University of Denmark, Søborg, Denmark

\author{
Correspondence \\ should be addressed \\ to A Krejbjerg \\ Email \\ anne.krejbjerg@rn.dk
}

\begin{abstract}
Objective: Our objective was to investigate individual serum thyroglobulin (Tg) changes in relation to iodine fortification (IF) and to clarify possible predictors of these changes.

Design: We performed a longitudinal population-based study (DanThyr) in two regions with different iodine intake at baseline: Aalborg (moderate iodine deficiency (ID)) and Copenhagen (mild ID). Participants were examined at baseline (1997) before the mandatory IF of salt (2000) and again at follow-up (2008) after IF.

Methods: We examined 2465 adults and a total of 1417 participants with no previous thyroid disease and without Tg-autoantibodies were included in the analyses. Serum Tg was measured by immunoradiometric method. We registered participants with a daily intake of iodine from supplements in addition to IF.

Results: Overall, the follow-up period saw no change in median Tg in Copenhagen (9.1/9.1 $\mu \mathrm{g} / \mathrm{l}, P=0.67)$ while Tg decreased significantly in Aalborg (11.4/9.0 $\mu \mathrm{g} / \mathrm{l}, P<0.001)$. Regional differences were evident before IF (Copenhagen/Aalborg,

9.1/11.4 $\mu \mathrm{g} / \mathrm{l}, P<0.001)$, whereas no differences existed after IF $(9.1 / 9.0 \mu \mathrm{g} / \mathrm{l}, P=1.00)$. Living in Aalborg $(P<0.001)$ and not using iodine supplements at baseline $(P=0.001)$ predicted a decrease in $\mathrm{Tg}$ whereas baseline thyroid enlargement $(P=0.02)$ and multinodularity $(P=0.01)$ were associated with an individual increase in Tg during follow-up.

Conclusions: After IF we observed a decrease in median Tg in Aalborg and the previously observed regional differences between Aalborg and Copenhagen had levelled out. Likewise, living in Aalborg was a strong predictor of an individual decrease in serum Tg. Thus, even small differences in iodine intake at baseline were very important for the individual response to IF.
\end{abstract}

\section{Introduction}

Iodine is an essential part of thyroid hormones and therefore iodine is needed for normal metabolism, growth and development $(1,2,3)$. Low iodine intake causes iodine deficiency (ID)-related disorders that have affected billions of people worldwide $(4,5)$.

Thyroglobulin $(\mathrm{Tg})$ is a $660 \mathrm{kDa}$ protein exclusively synthesized by thyroid epithelial cells organized in follicular structures. Tg plays an important role as a matrix
European Journal of

Endocrinology

(2015) 173, 573-581 (c) 2015 European Society of Endocrinology Printed in Great Britain in the synthesis and storage of the thyroid hormone in the follicular lumen (6). In the 1960s a new sensitive RIA method detected Tg in monkey and human serum, challenging the belief that $\mathrm{Tg}$ did not leave the thyroid gland $(7,8)$. These observations lead to further studies investigating changes in circulating Tg during the $1970 \mathrm{~s}$ $(9,10)$ where Van Herle et al. (10) described a high mean serum Tg among residents of an endemic goitre region. 
In 1985 these observations were confirmed and extended by Fenzi et al. (11) who investigated residents of a moderate endemic goitre area. Since then RIAs and screening for $\mathrm{Tg}$ autoantibodies (Tg-Ab) were improved (12) and several studies found an inverse association between iodine intake and serum $\operatorname{Tg}(13,14,15,16,17)$. Therefore, it has been suggested that serum $\mathrm{Tg}$ values in a population is a sensitive marker of iodine intake, and that serum $\mathrm{Tg}$ can be used to monitor the iodine status of a population. However, only few studies have investigated serum $\mathrm{Tg}$ in relation to iodine fortification (IF) $(18,19$, 20,21 ), and no previous longitudinal study gave information on serum Tg both before and after IF.

Our study is a prospectively planned 11-year follow-up study performed in two Danish regions with different iodine intake at baseline. Baseline information on serum Tg was obtained before the mandatory IF initiated in year 2000 and the follow-up study was performed 8.6 years after IF. The main goal of our study was to investigate individual serum Tg changes in relation to IF and to clarify possible predictors of these changes. In addition, we wanted to elucidate serum Tg levels in the Danish population using both our longitudinal data and data from a previous cross-sectional study performed 4 years after IF.

\section{Subjects and methods}

\section{Study population and design}

In 1997-1998 a cross-sectional study (Cohort 1a (C1a)) was performed in two regions of Denmark with mild (Copenhagen) and moderate (Aalborg) ID. The study was a part of the DanThyr program monitoring the mandatory Danish nationwide IF of salt. The IF was initiated in year 2000 and consisted of adding $13 \mu \mathrm{g}$ iodine/g salt in household salt and into salt for the production of bread. The program was designed to increase the average daily iodine intake among adult Danes by $50 \mu \mathrm{g}$ (22). Participants were chosen at random within specific age and sex groups using the Danish civil registration system: women aged 18-22 years, 25-30 years, 40-45 years and 60-65 years and men aged 60-65 years. A total of 4649 subjects participated $(50.1 \%$ of the invited): 2429 participants in Copenhagen and 2220 participants in Aalborg. Median urinary iodine concentration (UIC) in Copenhagen was $68 \mu \mathrm{g} / 1$ (61 $\mu \mathrm{g} / \mathrm{l}$ in participants not taking iodine supplements) and in Aalborg median UIC was $53 \mu \mathrm{g} / 1$ $(45 \mu \mathrm{g} / \mathrm{l})$. The study of this cohort was described in detail previously (18).
As a part of the monitoring program, a second cross-sectional study (Cohort 2 (C2)) was performed in 2004-2005 after IF in year 2000. The C2 study comprised participants selected in the same regions and within the same age and sex groups as in $\mathrm{C} 1 \mathrm{a}$, thus making the two cohorts directly comparable. A total of 3570 subjects participated (46.6\% of those invited). Median UIC in Copenhagen was $108 \mu \mathrm{g} / \mathrm{l}(99 \mu \mathrm{g} / 1$ in non-supplementusers) and median UIC in Aalborg was $93 \mu \mathrm{g} / \mathrm{l}(86 \mu \mathrm{g} / \mathrm{l})$ classifying Copenhagen as iodine sufficient and Aalborg as mildly iodine deficient according to WHO (23). Details of the study have previously been published (21).

From February 2008 to February 2010, we conducted a follow-up investigation (Cohort $1 \mathrm{~b}(\mathrm{C} 1 \mathrm{~b})$ ) of the first cross-sectional study (C1a). Of the 4649 participants in C1a, 72 subjects had emigrated (out of the country) and 403 subjects deceased during follow-up, allowing 4174 subjects to be invited for participation in C1b. The mean follow-up time was 11.2 years (range: $10.1-12.8$ years) and 2465 subjects participated, corresponding to $59.1 \%$ of the invited (Fig. 1). The examinations were performed at the Centre for Prevention of Goitre and Thyroid Diseases at

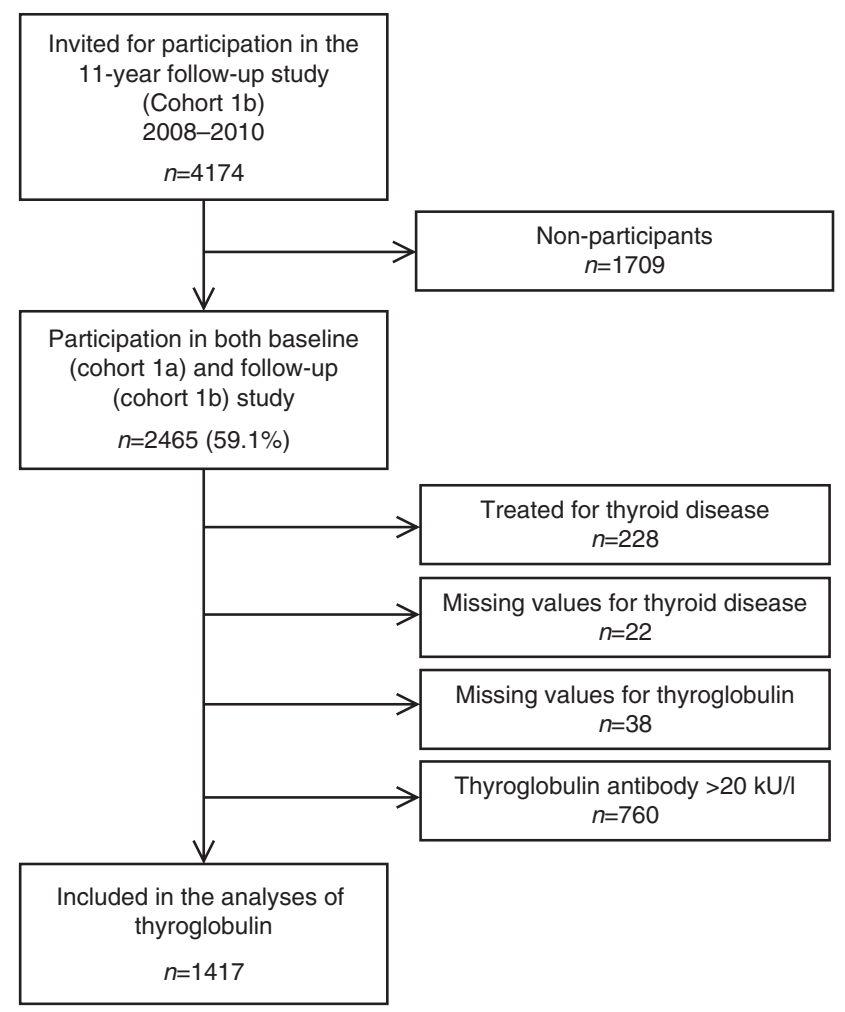

Figure 1

Flowchart illustrates participants included in the final study population of the follow-up Cohort $1 \mathrm{~b}$. 
either Aalborg University Hospital or Bispebjerg University Hospital in the region of Copenhagen. At each centre a team including a physician and a sonographer performed the examinations. The participants answered questionnaires (health, food frequency and food supplements), gave blood and urine samples, underwent a physical examination, had a thyroid ultrasonography performed and were interviewed.

Participants were asked to bring with them all dietary supplements taken, and daily intake of iodine from supplements was registered. Owing to the planned follow-up design, all procedures were kept similar in the baseline and in the follow-up study. Median UIC in Copenhagen at follow-up was $84 \mu \mathrm{g} / 1$ (76 $\mu \mathrm{g} / \mathrm{l}$ for participants not taking iodine supplementation) and in Aalborg median iodine concentration was $83 \mu \mathrm{g} / \mathrm{l}(73 \mu \mathrm{g} / \mathrm{l})$, classifying both Copenhagen and Aalborg as mildly iodine deficient (24).

Participants differed from non-participants of the follow-up study on baseline smoking status, BMI and presence of TPO-Ab (25). The thyroid ultrasonography examinations were performed as described in detail previously (25).

\section{Laboratory procedures}

Non-fasting blood samples and non-fasting spot urine samples were collected between $0800 \mathrm{~h}$ and $1730 \mathrm{~h}$. Serum and urine samples were kept frozen $\left(-20^{\circ} \mathrm{C}\right)$ and analysed in random order at the study end.

In the baseline study (C1a), serum Tg was analysed with immunoluminometric assays (LUMITEST, BRAHMS Diagnostica GmbH, Berlin, Germany) by a Stratec autoanalyzer (STRATEC Biomedical Systems AG, Birkenfeld, Germany). The effective working range of the assay was $1-500 \mu \mathrm{g} / \mathrm{l}$. In 12 consecutive assays the inter-assay coefficients of variation $(\mathrm{CV})$ for samples measured with average Tg concentrations of $8.1,45$ and $154 \mu \mathrm{g} / 1$ were 6.8 , 4.5 and $3.3 \%$.

In the second cross-sectional study (C2) and in the follow-up study (C1b) serum Tg was measured using an immunofluorescent assay (hTg KRYPTOR, BRAHMS) with a functional assay sensitivity below $0.8 \mathrm{ng} / \mathrm{ml}$ (information from manufacturer). In 115 consecutive assays the inter-assay CV for samples with average Tg concentrations of 3.3 and $50.5 \mu \mathrm{g} / \mathrm{l}$ were 5.6 and $2.8 \%$.

To allow direct comparison between baseline and follow-up $\mathrm{Tg}$ values, we measured $\mathrm{Tg}$ in 101 random antibody-negative serum samples kept frozen from the baseline study with the new assay. There was a high correlation between the two methods $\left(r_{\mathrm{s}}=0.98\right)$ but a Bland-Altman plot showed differences in the level of measurement results. A linear regression model showed Tg $($ follow-up) $=1.487+0.693 \times \mathrm{Tg}$ (baseline). This equation was used to adjust Tg measured at baseline to the assay used at follow-up and adjusted baseline Tg was used in all data analyses.

In the $\mathrm{C} 1 \mathrm{a}$ cohort, $\mathrm{Tg}-\mathrm{Ab}$ were measured using RIA (DYNOtest, BRAHMS) with functional assay sensitivity at $20 \mathrm{kU} / \mathrm{l}$. In C2 and C1b Tg-Ab were analysed with an immunofluorescent assay (anti-Tgn KRYPTOR, BRAHMS). We re-measured $\mathrm{Tg}-\mathrm{Ab}$ in 201 sera (106 $\mathrm{Tg}$-Ab positive) kept frozen from the baseline study with the new assay. Correlation was high $\left(r_{\mathrm{s}}=0.94\right)$ and a Bland-Altman plot showed a high level of agreement between the two methods. Thus, we used a cut-off of $20 \mathrm{kU} / 1$ to indicate $\mathrm{Tg}-\mathrm{Ab}$ positivity in both $\mathrm{C} 1 \mathrm{a}, \mathrm{C} 2$ and $\mathrm{C} 1 \mathrm{~b}$.

Iodine concentrations $(\mu \mathrm{g} / \mathrm{l})$ were measured in the non-fasting spot urine samples by the $\mathrm{Ce}^{4+} / \mathrm{As}^{3+}$ method after alkaline ashing as previously described $(26,27)$. The analytical sensitivity was $2 \mu \mathrm{g} / \mathrm{l}$ and the iodine laboratory is certified by the US Center for Disease Control and Prevention's EQUIP Program.

\section{Statistical analysis}

All data processing was done with the STATA version 11.0 (Stata Corp., College Station, TX, USA). Comparisons were made using the $\chi^{2}$ test for categorical variables and Mann-Whitney's $U$ test for medians of continuous variables. Comparisons between related continuous variables were made with Wilcoxon Signed Rank test. Two-sided $P<0.05$ was considered statistically significant.

Participants treated for thyroid disease (current or previous treatment with medicine, surgery or radioactive iodine therapy) at baseline or at follow-up $(n=228)$, participants with missing values on treatment for thyroid disease or serum Tg concentration $(n=60)$ and participants with $\mathrm{Tg}-\mathrm{Ab}>20 \mathrm{kU} / 1(n=760)$, were excluded from primary analyses, leaving 1417 participants for the analyses (Fig. 1).

Multiple linear regression models were used to investigate possible baseline predictors of individual changes in Tg. The primary model included only women and a separate model restricted to men and women aged 60-65 years was used to investigate if sex was associated with individual changes in Tg. The models used individual changes in $\mathrm{Tg}$ as outcome variable and included: age, region and at baseline: usage of iodine supplements, thyroid enlargement, multinodularity, daily smoking, 
alcohol consumption and childbirths as possible predictors. Interactions between relevant variables were investigated and a significant interaction between region and smoking was observed $(P=0.001)$.

\section{Ethics}

The study protocols were approved by the Danish Ethics Committee (2-16-4-0001-97 and VN 96/208mch and N-VN-19960208MCH, the Northern Danish Region Committee). The study was performed in accordance with the Declaration of Helsinki and all participants gave written informed consent.

\section{Results}

\section{Study population}

As depicted in Table 1, median $\mathrm{Tg}$ at inclusion in 1997-1998 did not differ between participants and non-participants of the 2008-2010 follow-up study C1b.

\section{Thyroglobulin}

When we compared median serum $\mathrm{Tg}$ before and after IF by paired analyses of our follow-up cohort $(n=1417)$ no significant changes in $\mathrm{Tg}$ were observed in Copenhagen whereas median $\mathrm{Tg}$ had decreased in all age and sex groups in Aalborg (Table 2). Before IF, regional differences in median Tg were evident in all groups except 60-65year-old women. In contrast, no regional differences in $\mathrm{Tg}$ were observed after IF.

\section{Predictors of Tg change}

Iodine intake level at baseline (higher in Copenhagen than Aalborg, see Methods) was a strong predictor of individual change in Tg after IF. Thus, participants from Aalborg (formerly moderate ID) were more likely to have a decrease in serum $\mathrm{Tg}$ compared with participants living in Copenhagen (formerly mild ID) (Table 3 ). In addition, no use of iodine containing supplements at baseline was a predictor of a decrease in serum Tg during follow-up compared with iodine supplement users at baseline.

Baseline thyroid enlargement and multinodularity predicted an individual increase in serum $\mathrm{Tg}$ during the 11-year follow-up period, whereas daily smoking, alcohol consumption and parity at baseline did not predict changes in Tg during the follow-up period (Table 3).

In additional analysis, we found a larger decrease in serum $\mathrm{Tg}$ among participants who stopped smoking during follow-up $(n=178)$ compared with participants without changes in their smoking habits $(n=515)$ (median individual $\mathrm{Tg}$ change $-2.5 /-0.8 \mu \mathrm{g} / \mathrm{l}$, $P<0.001)$. No difference in $\mathrm{Tg}$ change was found between the few participants $(n=20)$ who started smoking and participants without any change in their smoking habits $(1.0 /-0.8 \mu \mathrm{g} / \mathrm{l}, P=0.35)$.

Table 1 Median thyroglobulin at inclusion according to baseline characteristics of participants and non-participants in the followup study C1b. Comparisons between participants and nonparticipants were made using Mann-Witney's test.

\begin{tabular}{|c|c|c|c|c|c|}
\hline \multirow[b]{2}{*}{ Baseline characteristics } & \multicolumn{2}{|c|}{ Participants $(n=2465)$} & \multicolumn{2}{|c|}{ Non-participants $(n=1709)$} & \multirow[b]{2}{*}{$\boldsymbol{P}^{\mathrm{a}}$} \\
\hline & $n(\%)$ & $\begin{array}{c}\text { Median Tg } \\
\text { (25th-75th percentiles) }\end{array}$ & $n(\%)$ & $\begin{array}{c}\text { Median Tg } \\
\text { (25th-75th percentiles) }\end{array}$ & \\
\hline \multicolumn{6}{|l|}{ Age groups } \\
\hline Women, $18-22$ years & $489(19.8)$ & $9.6(5.1-18.1)$ & $434(25.4)$ & $10.7(5.9-17.8)$ & 0.10 \\
\hline Women, $25-30$ years & $514(20.9)$ & $11.7(6.1-21.2)$ & 391 (22.9) & $11.2(6.0-21.4)$ & 0.98 \\
\hline Women, $40-45$ years & $657(26.7)$ & $14.4(6.9-27.3)$ & $237(13.9)$ & $13.7(7.2-27.1)$ & 0.78 \\
\hline Women, $60-65$ years & $381(15.5)$ & $14.0(5.2-30.2)$ & $366(21.4)$ & $16.4(7.1-32.2)$ & 0.11 \\
\hline Men, $60-65$ years & $424(17.2)$ & $11.6(5.5-21.5)$ & $281(16.4)$ & $12.8(6.1-24.1)$ & 0.07 \\
\hline \multicolumn{6}{|l|}{ Region } \\
\hline Copenhagen & $1236(50.1)$ & $10.6(5.3-19.3)$ & $899(52.6)$ & $10.6(5.7-19.3)$ & 0.57 \\
\hline Aalborg & 1229 (49.9) & $13.9(6.6-27.0)$ & $810(47.4)$ & $15.1(7.9-30.0)$ & 0.06 \\
\hline Daily smokers & 793 (32.2) & $16.8(8.9-28.9)$ & $668(39.1)$ & $15.6(8.5-30.4)$ & 0.54 \\
\hline Family history of thyroid disease & 507 (20.6) & $13.2(6.5-23.5)$ & $309(18.1)$ & $13.1(6.3-27.2)$ & 0.76 \\
\hline Treated for thyroid disease & $104(4.2)$ & $17.3(2.6-47.3)$ & $84(4.9)$ & $13.0(4.2-25.9)$ & 0.33 \\
\hline Thyroid enlargement ( $>18 / 25 \mathrm{ml}$ ) & $468(19.0)$ & $24.9(11.5-48.9)$ & $282(16.6)$ & $26.3(13.4-48.1)$ & 0.22 \\
\hline \multicolumn{6}{|l|}{ Thyroid nodularity } \\
\hline Solitary nodule & $353(14.3)$ & $15.8(6.6-29.2)$ & $215(12.6)$ & $17.0(8.1-33.4)$ & 0.17 \\
\hline Multiple nodules & $374(15.2)$ & $22.7(11.1-45.5)$ & $258(15.1)$ & $21.3(10.9-39.2)$ & 0.52 \\
\hline
\end{tabular}

www.eje-online.org 
Table 2 Median thyroglobulin level in two areas with formerly mild (Copenhagen) and formerly moderate ID (Aalborg). All participants were investigated both before (1997-1998) IF (2000) and at 11 years follow-up (2008-2010). Data represent median thyroglobulin level in $\mu \mathrm{g} /$ litre $\left(25^{\text {th }}-75^{\text {th }}\right.$ percentiles). Only values from participants of both studies (C1a and C1b) were included. Subjects treated for thyroid disease $(n=228)$ and participants with Tg-Ab $>20 \mathrm{kU} / \mathrm{l}$ at either baseline or follow-up $(n=760)$ were excluded. Data on thyroglobulin were missing for 38 subjects. Comparisons were made using Wilcoxon Sign Rank and Mann-Whitney's test.

\begin{tabular}{|c|c|c|c|c|c|c|c|c|}
\hline \multirow[b]{2}{*}{ Group $^{a}$} & \multicolumn{3}{|c|}{ Formerly mild ID (Copenhagen) } & \multicolumn{3}{|c|}{ Formerly moderate ID (Aalborg) } & \multirow{2}{*}{$\begin{array}{c}\text { Copenhagen } \\
\text { vs Aalborg, } \\
\text { before } \\
\text { iodization, P }\end{array}$} & \multirow{2}{*}{$\begin{array}{c}\text { Copenhagen } \\
\text { vs Aalborg, } \\
\text { after } \\
\text { iodization, P }\end{array}$} \\
\hline & $\begin{array}{l}\text { Before iodization } \\
\qquad n=750\end{array}$ & $\begin{array}{l}\text { After iodization } \\
\qquad n=750\end{array}$ & $P$ & $\begin{array}{l}\text { Before iodization } \\
\qquad n=667\end{array}$ & $\begin{array}{l}\text { After iodization } \\
\quad n=667\end{array}$ & $P$ & & \\
\hline \multicolumn{9}{|l|}{ Women } \\
\hline 18-22 years & $7.2(5.2-11.9)$ & $7.3(4.9-12.1)$ & 0.21 & $10.2(6.0-16.5)$ & $8.4(5.1-13.0)$ & $<0.001$ & 0.001 & 0.29 \\
\hline $25-30$ years & $8.9(5.6-13.6)$ & $8.2(5.4-12.7)$ & 0.19 & $10.3(6.5-17.8)$ & $8.6(5.4-12.9)$ & $<0.001$ & 0.01 & 0.91 \\
\hline $40-45$ years & $10.7(6.1-17.7)$ & $10.9(6.6-17.7)$ & 0.58 & $15.4(7.8-24.1)$ & $10.9(6.1-19.0)$ & $<0.001$ & $<0.001$ & 0.76 \\
\hline 60-65 years & $11.4(6.7-16.4)$ & $12.0(7.6-18.4)$ & 0.09 & $12.6(7.4-22.9)$ & $9.9(6.3-17.3)$ & 0.01 & 0.34 & 0.28 \\
\hline Men, 60-65 years & $8.3(4.6-14.2)$ & $8.3(4.6-13.9)$ & 0.51 & $10.2(6.1-17.8)$ & $7.7(4.7-12.4)$ & $<0.001$ & 0.01 & 1.00 \\
\hline Total & $9.1(5.5-14.9)$ & $9.1(5.5-15.3)$ & 0.67 & $11.4(6.4-19.3)$ & $9.0(5.4-14.9)$ & $<0.001$ & $<0.001$ & 1.00 \\
\hline
\end{tabular}

${ }^{a}$ Age at baseline. After IF participants were in average 11.2 years older.

Individual changes in serum $\mathrm{Tg}$ were not different among participants who changed their alcohol habits compared to those with the same alcohol consumption at both baseline and follow-up $(n=735)$ (decreased alcohol consumption $(n=254):-0.5 /-0.7 \mu \mathrm{g} / \mathrm{l}, P=0.88$; increased alcohol consumption $(n=102)$ : $-0.4 /-0.7 \mu \mathrm{g} / \mathrm{l}$, $P=0.33$ ).

Median serum $\mathrm{Tg}$ at baseline was higher among parous women than nulliparous women $(11.4 / 8.8 \mu \mathrm{g} / 1, P<0.001)$. At follow-up more women were parous, and no difference in median $\mathrm{Tg}$ was found between the two groups $(9.1 / 8.1 \mu \mathrm{g} / 1, P=0.22)$. Furthermore, the individual changes in serum $\mathrm{Tg}$ were not different in women who gave birth during follow-up $(n=537)$ compared with those who did not $(n=388)(-0.9 /-1.0 \mu \mathrm{g} / \mathrm{l}, P=0.79)$.

\section{lodine supplements and $\mathrm{Tg}$}

At baseline, 475 participants (33.5\%) took iodinecontaining supplements and at follow-up 252 had stopped and 266 had started taking supplements. This resulted in 489 participants (34.5\%) taking iodine supplements at the follow-up investigation. Before IF, median Tg was significantly lower among iodine supplement users than nonusers $(8.1 / 11.2 \mu \mathrm{g} / \mathrm{l}, P<0.001)$ in both regions (Fig. 2). Furthermore, a regional difference in median Tg was evident for those participants not taking iodine supplements $(P<0.001)$, whereas no statistically significant regional difference in $\mathrm{Tg}$ was found for iodine supplement users $(P=0.25)$.

After IF, median $\mathrm{Tg}$ was still significantly lower among iodine supplement users than among non-users
(7.9/9.4 $\mu \mathrm{g} / \mathrm{l}, P=0.001$ ) in both regions (Fig. 2). Median Tg for iodine supplement users was at the same level as before IF, whereas median Tg for non-users had decreased in Aalborg after IF and the regional difference among nonusers had disappeared $(P=0.99)$.

Participants not taking iodine supplements at baseline before IF had a significant decrease in median Tg during the follow-up period (non-users at both baseline and follow-up ( $n=676)$ : 11.5/9.6 $\mu \mathrm{g} / \mathrm{l}, \quad P<0.001$; non-users who started taking supplements $(n=266)$ : 10.2/7.6 $\mu \mathrm{g} / \mathrm{l}$, $P<0.001)$. No change in median Tg was found among participants taking iodine supplements at both baseline and follow-up $(n=223)(8.1 / 8.8 \mu \mathrm{g} / \mathrm{l}, P=0.81)$. Users at baseline who stopped taking supplements during followup $(n=252)$ had a borderline increase in $\mathrm{Tg}(8.3 / 9.1 \mu \mathrm{g} / \mathrm{l}$, $P=0.06)$.

\section{Tg trends in the DanThyr cohorts}

Median values of $\mathrm{Tg}$ in the cohorts investigated in DanThyr are shown in Fig. 3 and for this we used data from all participants investigated. Before IF (C1a) median $\mathrm{Tg}$ was higher in Aalborg (moderate ID) than Copenhagen (mild ID) in all age and sex groups. Furthermore, median Tg was higher in women 60-65 years old than in men 60-65 years old $(P<0.001)$ and there was an agedependent increase in median $\mathrm{Tg}$ among women.

After IF, similar patterns were seen for $\mathrm{C} 2$ investigated in 2004-2005 and for C1b investigated in 2008-2010: median $\mathrm{Tg}$ had become lower in all age and sex groups in Aalborg and the regional difference in median $\mathrm{Tg}$ had disappeared in all age and sex groups. The age-dependent 
Table 3 Predictors of Thyroglobulin change at 11-year followup. Multiple linear regression model with change in serum $\mathrm{Tg}$ as outcome variable and baseline characteristics as predictor variables. The estimate defines the number of units of change in serum $\operatorname{Tg}(y)$ in the specific class of the predictor $(x)$ compared with the reference group (ref.). Participants treated for thyroid disease $(n=228)$ and participants with $\mathrm{Tg}-\mathrm{Ab}>20 \mathrm{kU} / \mathrm{l}$ at either baseline or follow-up were excluded from the analysis $(n=760)$. The primary model included Tg-Ab negative women $(n=1110)$, sex as a predictor of change in serum $\mathrm{Tg}$ was analysed in a separate model restricted to women and men aged 60-65 years $(n=480)$.

\begin{tabular}{l} 
Baseline characteristics \\
\hline Age \\
Women, $18-22$ years \\
Women, $25-30$ years \\
Women, $40-45$ years \\
Women, $60-65$ years \\
Sex \\
Women, $60-65$ years \\
Men, 60-65 years \\
Region \\
Copenhagen \\
Aalborg \\
lodine supplements at baseline \\
Yes \\
No \\
Thyroid enlargement at baseline \\
( $>18 / 25$ ml by US) \\
No \\
Yes \\
Multinodularity ( $\geq 2$ thyroid \\
nodules) \\
No \\
Yes \\
Daily smoking at baseline \\
No \\
Yes \\
Alcohol consumption at baseline \\
$<1$ drink/week \\
$1-7$ drinks/week \\
$8-28$ drinks/week \\
$>28$ drinks/week \\
Parity at baseline \\
Nulliparous \\
Parous \\
\end{tabular}

\begin{tabular}{|c|c|c|}
\hline$n$ & Estimate & $\boldsymbol{P}$ \\
\hline $\begin{array}{l}283 \\
285 \\
369 \\
173\end{array}$ & $\begin{array}{l}\text { Ref. } \\
-0.679 \\
-0.710 \\
2.773\end{array}$ & $\begin{array}{l}0.52 \\
0.58 \\
0.06\end{array}$ \\
\hline $\begin{array}{l}173 \\
307\end{array}$ & $\begin{array}{l}\text { Ref. } \\
2.408\end{array}$ & 0.101 \\
\hline $\begin{array}{l}596 \\
514\end{array}$ & $\begin{array}{l}\text { Ref. } \\
-3.268\end{array}$ & $<0.001$ \\
\hline $\begin{array}{l}382 \\
728\end{array}$ & $\begin{array}{c}\text { Ref. } \\
-2.553\end{array}$ & 0.001 \\
\hline $\begin{array}{l}940 \\
169\end{array}$ & $\begin{array}{l}\text { Ref. } \\
2.562\end{array}$ & 0.02 \\
\hline $\begin{array}{l}661 \\
148\end{array}$ & $\begin{array}{l}\text { Ref. } \\
2.902\end{array}$ & 0.01 \\
\hline $\begin{array}{l}717 \\
393\end{array}$ & $\begin{array}{c}\text { Ref. } \\
-0.823\end{array}$ & 0.29 \\
\hline $\begin{array}{r}142 \\
705 \\
249 \\
12\end{array}$ & $\begin{array}{c}\text { Ref. } \\
-0.275 \\
-0.520 \\
-1.427\end{array}$ & $\begin{array}{l}0.80 \\
0.68 \\
0.69\end{array}$ \\
\hline $\begin{array}{l}441 \\
669\end{array}$ & $\begin{array}{l}\text { Ref. } \\
-1.286\end{array}$ & 0.20 \\
\hline
\end{tabular}

${ }^{a}$ Age at baseline. At follow-up participants were on average 11.2 years older.

increase in median Tg was still evident but had levelled out. The sex-dependent difference in median $\mathrm{Tg}$ had decreased, but $\mathrm{Tg}$ was still significantly lower among men than women $(P<0.001)$. Participants investigated in 2008-2010 (C1b) were selected among participants of $\mathrm{C} 1 \mathrm{a}$ and were on average 11.2 years older than participants of $\mathrm{C} 1 \mathrm{a}$ and $\mathrm{C} 2$. To take age differences into account we compared median Tg in 40-41-year-old women in C1a, C2 and $\mathrm{C} 1 \mathrm{~b}$, and found a significantly higher median $\mathrm{Tg}$ in
C1a compared with $\mathrm{C} 2(17.1 / 8.5 \mu \mathrm{g} / \mathrm{l}, \quad P<0.001)$ and compared with $\mathrm{C} 1 \mathrm{~b}(17.1 / 7.7 \mu \mathrm{g} / \mathrm{l}, P<0.001)$. We found no difference in median Tg among 40-41-year-old women between $\mathrm{C} 2$ and $\mathrm{C} 1 \mathrm{~b}(8.5 / 7.7 \mu \mathrm{g} / \mathrm{l}, P=0.15)$.

\section{Discussion}

\section{Principal findings}

We performed an 11-year follow-up investigation where participants were examined 8.6 years after the Danish mandatory IF of salt $(13 \mu \mathrm{g} / \mathrm{g})$ in two regions with different iodine intakes at baseline: Aalborg (moderate ID) and Copenhagen (mild ID). During the follow-up period, no change in median $\mathrm{Tg}$ was observed in Copenhagen while Aalborg had a decrease in median $\mathrm{Tg}$ in all age and sex groups. Additionally, regional differences were evident in all groups except the oldest group of women before IF, whereas no regional differences existed after IF. Living in Aalborg and not using iodine supplements at baseline were strong predictors of a decrease in serum $\mathrm{Tg}$. Thus, degree of ID at baseline was the dominating predictor of a change in serum Tg. Furthermore, baseline thyroid enlargement and multinodularity were associated with

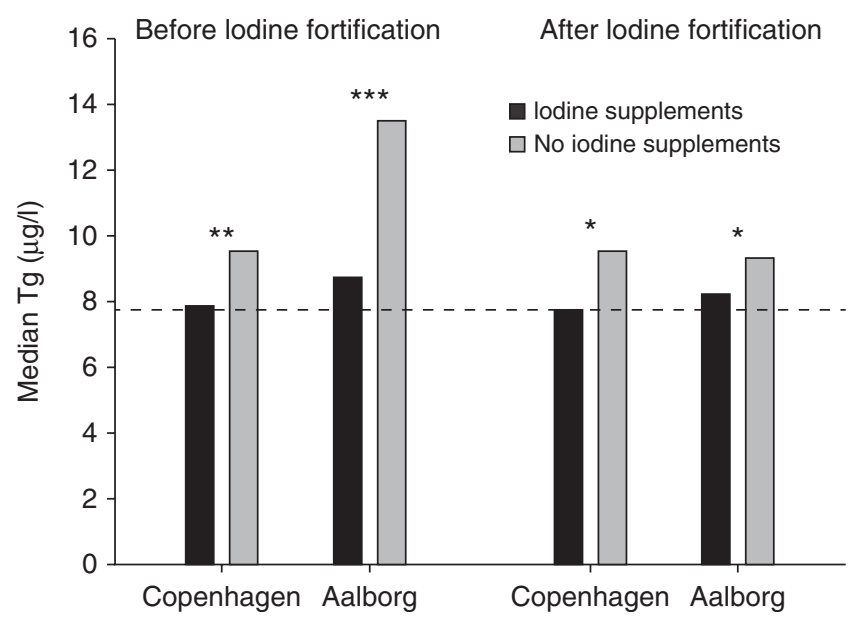

\section{Figure 2}

Median serum thyroglobulin $(\mu \mathrm{g} / \mathrm{l})$ by individual intake of iodine supplements in subjects who participated in both C1a (1997-98) and C1b (2008-10) according to region ( $n=1417)$. Nearly all supplements contained $150 \mu$ g iodine. To assist visual comparison, a line (horizontal stippled) has been added corresponding to the lowest value of median Tg found after IF in $\mathrm{C} 1 \mathrm{~b}$ among participants taking iodine supplements in Copenhagen $(\mathrm{Tg}=7.7 \mu \mathrm{g} / \mathrm{l}) .{ }^{*} P<0.05, * * P<0.01, * * * P<0.001$ in between intake of iodine supplement analyses. 


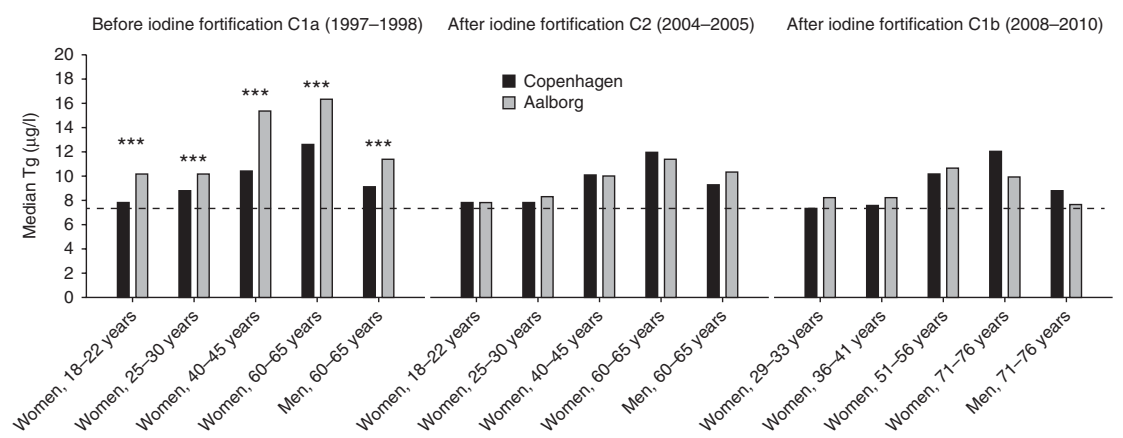

\section{Figure 3}

Median serum thyroglobulin $(\mu \mathrm{g} / \mathrm{l})$ by region in the DanThyr cohorts: C1a $(n=4649)$, C2 $(n=3570)$ and C1b $(n=2465)$ according to age and sex groups. Note that participants in $\mathrm{C} 1 \mathrm{~b}$ were on average 11.2 years older. Subjects treated for thyroid disease (C1a: $n=228, C 2: n=192$ and C1b: $n=228$ ) and subjects with Tg-Ab > $20 \mathrm{kU} / \mathrm{l}(\mathrm{C} 1 \mathrm{a}: n=599, \mathrm{C} 2: n=640$ and C1b: $n=649)$

an individual increase in serum $\mathrm{Tg}$ during follow-up whereas age per se had no predictive value.

In additional analyses, we found a higher median $\mathrm{Tg}$ among non-users of iodine containing supplements than among users both before and after IF. Regional differences in median Tg was only evident for non-users before IF.

\section{Previous studies}

Previous studies have investigated the relation between serum $\mathrm{Tg}$ and iodine intake in adult populations living in regions with different iodine intakes $(13,17,18,19,20,21)$. In accordance with our results, these studies found an inverse relation between serum $\mathrm{Tg}$ and iodine intake even in regions with small differences in iodine intake. Several studies concluded that even if serum $\mathrm{Tg}$ concentration is a non-specific marker of thyroid disease in the individual and even if Tg-Ab may influence measurements, Tg is a good marker of iodine intake in a population and that it is a useful tool in monitoring the iodine status $(14,18,21$, $28,29)$. However, only one previous longitudinal population-based cohort study has investigated serum $\mathrm{Tg}$ in relation to iodine intake. This 5-year follow-up study was performed by Teng et al. (20) in three regions of China with different iodine intakes at both baseline and followup (mild ID, adequate iodine intake and excessive iodine intake). They found a significant difference in serum $\mathrm{Tg}$ between the three regions with a higher median Tg in the region with mild ID. The study commenced 3 years after IF and the study population had a stable iodine intake during were excluded from the analyses. To assist visual comparison, a line (horizontal stippled) has been added corresponding to the lowest value of median Tg found after IF in C1b among 29-33 year old women in Copenhagen $(\mathrm{Tg}=7.3 \mu \mathrm{g} / \mathrm{l})$. ${ }^{*} * *<0.001 \mathrm{in}$ between region analyses.

the follow-up period. Individual changes in serum $\mathrm{Tg}$ during follow-up were not presented.

Other studies have investigated the relation between iodine intake and $\mathrm{Tg}$ in randomised trials $(15,16)$. Pedersen et al. (15) investigated Danish pregnant women in an area with moderate ID, whereas Kahaly et al. (16) studied German adult patients with clinical symptoms of endemic goitre in a moderate ID area. Both studies found a continuous decrease in serum Tg compared with the control group when iodine supplements were administered. When iodine supplementation was stopped, Kahaly et al. (16) reported an increase in serum $\mathrm{Tg}$ to the level before supplementation was initiated. This supports the notion that serum Tg is a good and sensitive marker of changes in iodine intake and it is in accordance with our findings.

However, measuring serum $\mathrm{Tg}$ is challenging (30) and different analysing methods as well as interference from circulating autoantibodies can hamper interpretation and make comparisons between studies difficult. Therefore we chose to exclude Tg-Ab-positive participants from our analysis although a previous investigation (21) showed that the exclusion of Tg-Ab-positive participants may not influence the interpretation of population-based data.

During the follow-up period, median UIC had increased to a level that classified both Aalborg and Copenhagen as mildly iodine deficient at follow-up (24). However, at follow-up, UIC were lower than observed in C2 examined 4-5 years after IF. A major cause for the observed decrease in iodine concentration may be a reduction in the iodine content of common milk products (31). 
Corresponding to the higher iodine intake in 20082010 compared with 1997-1998, serum Tg had decreased. The most prominent change occurred in Aalborg with the largest increase in median UIC. Likewise, multivariate regression analysis found living in Aalborg as well as no baseline usage of iodine supplements to be predictors of an individual decrease in serum $\mathrm{Tg}$. Thus, the degree of baseline ID was the dominating predictor of a change in serum Tg even though the baseline differences in UIC between Aalborg and Copenhagen were small (53 $\mu \mathrm{g} / \mathrm{l}$ vs $68 \mu \mathrm{g} / \mathrm{l}$, and in participants not taking iodine supplements: $45 \mu \mathrm{g} / \mathrm{l}$ vs $61 \mu \mathrm{g} / \mathrm{l})$. The difference in UIC is caused by differences in groundwater iodine content being around $5 \mu \mathrm{g} / \mathrm{l}$ in Aalborg and $20 \mu \mathrm{g} / 1$ in Copenhagen (32).

Despite the general decrease in serum $\mathrm{Tg}$, median $\mathrm{Tg}$ among non-users of iodine supplements was still higher than median Tg among iodine supplement users after IF. The iodization of salt initiated in $2000(13 \mu \mathrm{g} / \mathrm{g})$ was cautious in order to minimize side effects (22) and the results of the present study raise the question if a moderate increase in the level of iodine added to the salt, bringing median urinary iodine values to a level around $100 \mu \mathrm{g} / \mathrm{l}$ as found in 2004-2005 (21) could be beneficial for the Danish population. This conclusion is in accordance with the results of urinary iodine measurements, indicating that the C1b cohort investigated in 2008-2010 was in general suffering from mild ID (24). A cross-sectional study with participants from the same regions and in the same age and sex groups as in the two cross-sectional studies C1a and C2 would give epidemiologically more precise information on the iodine status of the Danish population.

\section{Strengths and limitations}

Our follow-up study had a relatively low participation rate of $59.1 \%$, which could lead to selection bias. However, baseline median Tg did not differ among participants and non-participants. The study population only included participants in specific age and sex groups, and although we have a relatively large study cohort, we cannot generalize our results to the entire population.

The strength of our study was the prospectively planned longitudinal design with investigation of participants both before and after IF, using identical procedures. Different assays were used for measuring serum $\mathrm{Tg}$ in $\mathrm{C} 1 \mathrm{a}$ vs C2 and C1b, but we adjusted C1a serum Tg to account for assay change. Part of the study results can be difficult to interpret because all participants of the follow-up study were 11 years older than in the baseline study. In the analyses of Fig. 3 we included data from the cross-sectional study C2 and considered C1a, C2 and C1b as three independent cohorts. This has limitations since $\mathrm{C} 1 \mathrm{a}$ and $\mathrm{C} 1 \mathrm{~b}$ were not independent. Moreover, participants of $\mathrm{C} 1 \mathrm{~b}$ were 11 years older.

We obtained information on daily intake of iodine supplements, but no information on the duration of iodine supplementation including seasonal variations was registered. This might influence our results and cause an attenuation of the association between median $\mathrm{Tg}$ and iodine supplement intake.

\section{Conclusions}

After the mandatory IF of salt, we observed a decrease in median serum $\mathrm{Tg}$ in Aalborg and the regional differences in serum Tg observed before IF had levelled out. Likewise, living in Aalborg was a strong predictor of a decrease in serum Tg. Thus, even small differences in iodine intake at baseline were very important predictors of the response to IF.

After IF median Tg among non-users of iodine supplements was still higher than median $\mathrm{Tg}$ among iodine supplement users and these results may raise the question if a moderate increase in the level of iodine added to the salt could be beneficial for the population in the study.

\section{Declaration of interest}

The authors declare that there is no conflict of interest that could be perceived as prejudicing the impartiality of the research reported.

\section{Funding}

This work was supported by the Danish Council for Independent Research; Medical Sciences; the 1991 Pharmacy Foundation; North Jutland County Research Foundation; Tømmerhandler Wilhelm Bangs Foundation; Copenhagen Hospital Corporation Research Foundation; Ministry of Food, Agriculture and Fisheries of Denmark; the Danish Agency for Science, Technology and Innovation and King Christian and Queen Louise Jubilee Scholarship.

\section{Acknowledgements}

We express our gratitude to Ingelise Leegaard and René Fiege for carefully performing the ultrasonografies and the laboratory work.

\section{References}

1 Delange F. The disorders induced by iodine deficiency. Thyroid $1994 \mathbf{4}$ 107-128. (doi:10.1089/thy.1994.4.107)

2 Zimmermann MB, Jooste PL \& Pandav CS. Iodine-deficiency disorders. Lancet 2008372 1251-1262. (doi:10.1016/S0140-6736(08)61005-3)

3 Laurberg P, Cerqueira C, Ovesen L, Rasmussen LB, Perrild H, Andersen S, Pedersen IB \& Carle A. Iodine intake as a determinant of thyroid disorders in populations. Best Practice \& Research. Clinical Endocrinology \& Metabolism 201024 13-27. (doi:10.1016/j.beem.2009.08.013) 
4 Kelly FC \& Snedden WW. Prevalence and distribution of endemic goitre. In Endemic Goitre, pp 27-233. Geneva, Switzerland: WHO, 1960.

5 Carle A, Krejbjerg A \& Laurberg P. Epidemiology of nodular goitre. Influence of iodine intake. Best Practice \& Research. Clinical Endocrinology \& Metabolism 201428 465-479. (doi:10.1016/j.beem.2014.01.001)

6 Lamas L \& Taurog A. The importance of thyroglobulin structure in thyroid peroxidase-catalyzed conversion of diiodotyrosine to thyroxine. Endocrinology 1977100 1129-1136. (doi:10.1210/endo-100-4-1129)

7 Daniel PM, Pratt OE, Roitt IM \& Torrigiani G. The release of thyroglobulin from the thyroid gland into thyroid lymphatics; the identification of thyroglobulin in the thyroid lymph and in the blood of monkeys by physical and immunological methods and its estimation by radioimmunoassay. Immunology 196712 489-504.

8 Roitt IM \& Torrigiani G. Identification and estimation of undegraded thyroglobulin in human serum. Endocrinology 196781 421-429. (doi:10.1210/endo-81-3-421)

9 Uller RP, Van Herle AJ \& Chopra IJ. Comparison of alterations in circulating thyroglobulin, triiodothyronine and thyroxine in response to exogenous (bovine) and endogenous (human) thyrotropin. Journal of Clinical Endocrinology and Metabolism 197337 741-745. (doi:10.1210/ jcem-37-5-741)

10 Van Herle AJ, Hershman JM, Hornabrook RW \& Chopra IJ. Serum thyroglobulin in inhabitants of an endemic goiter region of New Guinea. Journal of Clinical Endocrinology and Metabolism 197643 512-516. (doi:10.1210/jcem-43-3-512)

11 Fenzi GF, Ceccarelli C, Macchia E, Monzani F, Bartalena L, Giani C, Ceccarelli P, Lippi F, Baschieri L \& Pinchera A. Reciprocal changes of serum thyroglobulin and TSH in residents of a moderate endemic goitre area. Clinical Endocrinology 198523 115-122. (doi:10.1111/j.1365-2265. 1985.tb00205.x)

12 Laurberg P \& Pedersen KM. A sensitive radio-immunoassay for serum thyroglobulin - including a correct screening for thyroglobulin autoantibodies. Scandinavian Journal of Clinical and Laboratory Investigation 198747 685-689. (doi:10.3109/00365518709168930)

13 Gutekunst R, Smolarek H, Hasenpusch U, Stubbe P, Friedrich HJ, Wood WG \& Scriba PC. Goitre epidemiology: thyroid volume, iodine excretion, thyroglobulin and thyrotropin in Germany and Sweden. Acta Endocrinologica 1986112 494-501.

14 Pedersen KM, Borlum KG, Knudsen PR, Hansen ES, Johannesen PL \& Laurberg P. Urinary iodine excretion is low and serum thyroglobulin high in pregnant women in parts of Denmark. Acta Obstetricia et Gynecologica Scandinavica 198867 413-416. (doi:10.3109/00016348809004251)

15 Pedersen KM, Laurberg P, Iversen E, Knudsen PR, Gregersen HE, Rasmussen OS, Larsen KR, Eriksen GM \& Johannesen PL. Amelioration of some pregnancy-associated variations in thyroid function by iodine supplementation. Journal of Clinical Endocrinology and Metabolism 1993 77 1078-1083.

16 Kahaly G, Dienes HP, Beyer J \& Hommel G. Randomized, double blind, placebo-controlled trial of low dose iodide in endemic goiter. Journal of Clinical Endocrinology and Metabolism 199782 4049-4053. (doi:10.1210/ jcem.82.12.4416)

17 Laurberg P, Pedersen KM, Hreidarsson A, Sigfusson N, Iversen E \& Knudsen PR. Iodine intake and the pattern of thyroid disorders: a comparative epidemiological study of thyroid abnormalities in the elderly in Iceland and in Jutland, Denmark. Journal of Clinical Endocrinology and Metabolism 199883 765-769. (doi:10.1210/jcem.83.3.4624)

18 Knudsen N, Bulow I, Jorgensen T, Perrild H, Ovesen L \& Laurberg P. Serum $\mathrm{Tg}$ - a sensitive marker of thyroid abnormalities and iodine deficiency in epidemiological studies. Journal of Clinical Endocrinology and Metabolism 200186 3599-3603.
19 Rasmussen LB, Ovesen L, Bulow I, Jorgensen T, Knudsen N, Laurberg P $\&$ Perrild H. Relations between various measures of iodine intake and thyroid volume, thyroid nodularity, and serum thyroglobulin. American Journal of Clinical Nutrition 200276 1069-1076.

20 Teng W, Shan Z, Teng X, Guan H, Li Y, Teng D, Jin Y, Yu X, Fan C, Chong W et al. Effect of iodine intake on thyroid diseases in China. New England Journal of Medicine 2006354 2783-2793. (doi:10.1056/ NEJMoa054022)

21 Vejbjerg P, Knudsen N, Perrild H, Laurberg P, Carle A, Pedersen IB, Rasmussen LB, Ovesen L \& Jorgensen T. Thyroglobulin as a marker of iodine nutrition status in the general population. European Journal of Endocrinology/European Federation of Endocrine Societies 2009161 475-481. (doi:10.1530/EJE-09-0262)

22 Laurberg P, Jorgensen T, Perrild H, Ovesen L, Knudsen N, Pedersen IB, Rasmussen LB, Carle A \& Vejbjerg P. The Danish investigation on iodine intake and thyroid disease, DanThyr: status and perspectives. European Journal of Endocrinology/European Federation of Endocrine Societies 2006155 219-228. (doi:10.1530/eje.1.02210)

23 WHO, UNICEF, ICCIDD. Assessment of iodine deficiency disorders and monitoring their elimination. 3rd edn. Geneva: World Health Organization, 2007.

24 Rasmussen LB, Jorgensen T, Perrild H, Knudsen N, Krejbjerg A, Laurberg P, Pedersen IB, Bjergved L \& Ovesen L. Mandatory iodine fortification of bread and salt increases iodine excretion in adults in Denmark - a 11-year follow-up study. Clinical Nutrition 201433 1033-1040. (doi:10.1016/j.clnu.2013.10.024)

25 Krejbjerg A, Bjergved L, Pedersen IB, Carle A, Jorgensen T, Perrild H, Ovesen L, Rasmussen LB, Knudsen N \& Laurberg P. Iodine fortification may influence the age-related change in thyroid volume: a longitudinal population-based study (DanThyr). European Journal of Endocrinology/European Federation of Endocrine Societies 2014170 507-517. (doi:10.1530/EJE-13-0918)

26 Wilson B \& Van Zyl A. The estimation of iodine in thyroidal amino acids by alkaline ashing. South African Journal of Medical Sciences 196732 70-82.

27 Laurberg P. Thyroxine and 3,5,3'-triiodothyronine content of thyroglobulin in thyroid needle aspirates in hyperthyroidism and hypothyroidism. Journal of Clinical Endocrinology and Metabolism 1987 64 969-974. (doi:10.1210/jcem-64-5-969)

28 Zimmermann MB, Aeberli I, Andersson M, Assey V, Yorg JA, Jooste P, Jukic T, Kartono D, Kusic Z, Pretell E et al. Thyroglobulin is a sensitive measure of both deficient and excess iodine intakes in children and indicates no adverse effects on thyroid function in the UIC range of 100-299 $\mu \mathrm{g} / \mathrm{l}$ : a UNICEF/ICCIDD study group report. Journal of Clinical Endocrinology and Metabolism 201398 1271-1280. (doi:10.1210/jc. 2012-3952)

29 Ma ZF \& Skeaff SA. Thyroglobulin as a biomarker of iodine deficiency: a review. Thyroid 201424 1195-1209. (doi:10.1089/thy.2014.0052)

30 Spencer CA \& Wang CC. Thyroglobulin measurement. Techniques, clinical benefits, and pitfalls. Endocrinology and Metabolism Clinics of North America 199524 841-863.

31 Rasmussen LB, Carle A, Jorgensen T, Knuthsen P, Krejbjerg A, Perrild H, Bjergved L, Sloth JJ, Laurberg P \& Ovesen L. Iodine excretion has decreased in Denmark between 2004 and 2010 - the importance of iodine content in milk. British Journal of Nutrition 2014112 1993-2001. (doi:10.1017/S0007114514003225)

32 Pedersen KM, Laurberg P, Nohr S, Jorgensen A \& Andersen S. Iodine in drinking water varies by more than 100-fold in Denmark. Importance for iodine content of infant formulas. European Journal of Endocrinology/European Federation of Endocrine Societies 1999140 400-403. (doi:10. 1530/eje.0.1400400)

Received 31 March 2015

Revised version received 7 July 2015

Accepted 5 August 2015 